\author{
Stanisław WOLNY ${ }^{1}$ \\ Sławomir BADURA ${ }^{2}$
}

\title{
WYTRZYMALOŚĆ CIĘGIEN NOŚNYCH GÓRNICZEGO NACZYNIA WYDOBYWCZEGO
}

\begin{abstract}
Analiza okresowych badań skipów i klatek eksploatowanych w szybach jednej z kopalń wykazała że większość zarejestrowanych uszkodzeń elementów nośnych naczyń wydobywczych to pęknięcia o charakterze zmęczeniowym.

Celem wyeliminowania przyczyn powstawania uszkodzeń oraz zwiększenia trwałości naczyń wydobywczych, niezbędnym będzie prawdopodobnie wykonanie rekonstrukcji tych fragmentów naczyń, w których uszkodzenia te występują. Aby rekonstrukcja przyniosła oczekiwane rezultaty niezbędne jest poznanie przyczyn będących źródłem powstających pęknięć. Dlatego postanowiono przeprowadzić pomiary, których wyniki umożliwiłyby wyznaczenia wartości obciążeń cięgien, a w dalszej kolejności ocenę ich wytrzymałości i trwałości.

Wykonana analiza trwałości zmęczeniowej cięgien naczynia wydobywczego, wskazuje na możliwość rozwoju pęknięć zmęczeniowych w najbardziej wytężonych obszarach konstrukcji, w krótkiej perspektywie czasowej.
\end{abstract}

Słowa kluczowe: skipy górnicze, naprężenia cięgien, tesnometria, trwałość zmęczeniowa

\section{Wprowadzenie}

Analiza okresowych badań skipów i klatek eksploatowanych w szybach jednej z kopalń wykazała że większość zarejestrowanych uszkodzeń elementów nośnych naczyń wydobywczych, to pęknięcia o charakterze zmęczeniowym [1]. Przykładowo na rys. 1 pokazano miejsca występowania pęknięć dla skipów o udźwigu $\mathrm{Q}=17 \mathrm{Mg}$. W przypadku skipu o udźwigu $17 \mathrm{Mg}$, pęknięcia występują najczęściej w rejonie otworu wysypowego (punkt A na schemacie konstrukcji skipu (rys. 1)). Były to pęknięcia cięgien lub spoin. Na cztery badane konstrukcje skipów o udźwigu $\mathrm{Q}=17 \mathrm{Mg}$ w punkcie A zaobserwowano 12 pęknięć. Generalnie, dla pozostałych konstrukcji naczyń wydobywczych w tym klatek, pęknięcia rozwijają się głównie w cięgnach nośnych lub spoinach, w obszarach łączenia

\footnotetext{
${ }^{1}$ Autor do korespondencji / corresponding author: AGH-University of Science and Technology Faculty of Mechanical Engineering and Robotics Al. Mickiewicza 30, 30-059, Kraków, Poland, stwolny@ agh.edu.pl

2 AGH-University of Science and Technology Faculty of Mechanical Engineering and Robotics Al. Mickiewicza 30, 30-059, Kraków, Poland sbadura@agh.edu.pl
} 


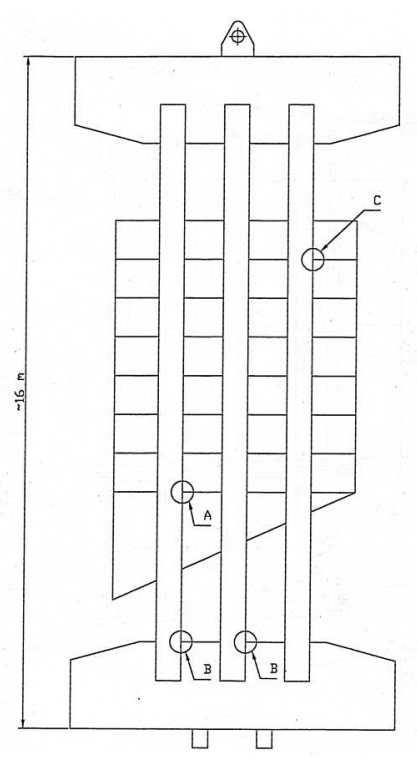

Rys. 1. Miejsce występowania pęknięć dla skipów o udźwigu $17 \mathrm{Mg}$

Fig. 1. Place cracks for conveyances with a capacity of $17 \mathrm{Mg}$

cięgien z konstrukcją naczynia. Pęknięcia te, o charakterze zmęczeniowym cięgien oraz spoin lub nitów łączących je z pozostałymi elementami konstrukcji, są najczęściej występującymi tego typu uszkodzeniami naczyń wydobywczych.

Celem wyeliminowania przyczyn powstawania uszkodzeń oraz zwiększenia trwałości naczynia, konieczne będzie prawdopodobnie wykonanie rekonstrukcji tych fragmentów naczyń wyciągowych, w których uszkodzenia te występują. Aby rekonstrukcja przyniosła oczekiwane rezultaty niezbędne jest poznanie przyczyn, będących źródłem powstających pęknięć

Należałoby sądzić, że poprawnie zaprojektowany skip lub klatka nie powinny ulegać uszkodzeniu o charakterze zmęczeniowym, biorąc pod uwagę wartości współczynników bezpieczeństwa $(\mathrm{n}=7)$ przyjmowanych do oceny ich wytrzymałości. Trzeba jednak wyjaśnić, że przyjmowane modele obliczeniowe elementów nośnych naczyń wydobywczych są bardzo uproszczone i nie w pełni oddają powstający w nich stan naprężeń wywołany przenoszonymi obciążeniami [2],[3]. Ponadto powszechną praktyką przy projektowaniu elementów nośnych konstrukcji naczyń wydobywczych jest wymiarowanie ich $\mathrm{z}$ warunku bezpieczeństwa, przy uwzględnieniu maksymalnego obciążenia statycznego [4].

W tym stanie rzeczy, niezbędnym stało się wykonanie stosownych pomiarów, które dałyby wiedze odnośnie obciążeń cięgien i w stanie naprężeń jaki jest w nich wywołany w pełnym cyklu eksploatacyjnym urządzenia wydobywczego. Dlatego postanowiono przeprowadzić pomiary, których wyniki umożliwiałyby wyznaczenie wartości obciążeń cięgien, a dalszej kolejności ocenę ich wytrzymałości i trwałości. 


\section{Pomiary tensometryczne na obiekcie rzeczywistym}

Mając na uwadze osiągnięcie zasygnalizowanych we wstępie celów, wyznaczenia obciążeń cięgien i wygenerowanych w nich naprężeniach w pełnym cyklu eksploatacyjnym, przeprowadzono tensometryczne pomiary odkształceń w jednej z polskich kopalń [1].

Pomiary tensometryczne przeprowadzono w najbardziej wytężonych przekrojach poprzecznych cięgien, szczególnie w obszarach w których powstają pęknięcia zmęczeniowe [1].

W tym celu skompletowano aparaturę pomiarową przedstawioną na rysunku 2, w skład której wchodziły mostki tensometryczne i komputery pomiarowe, umożliwiające rejestrację i obróbkę wyników pomiarów.

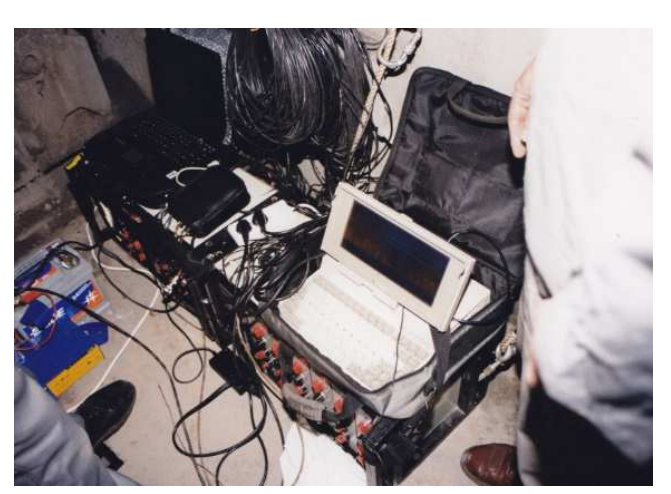

Rys. 2. Aparatura wykorzystana podczas pomiarów tensometrycznych

Fig. 2. The equipment used during the strain gauge measurements

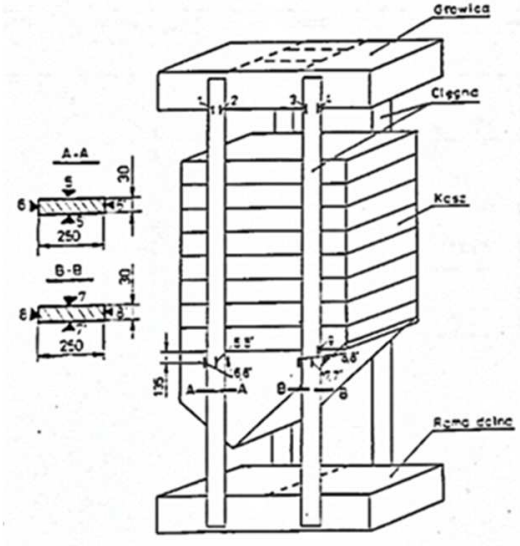

Rys. 3. Rozmieszczenie punktów pomiarowych na konstrukcji naczynia wydobywczego

Fig. 3. Placement of measurement points on the steel construction of conveyances

Schemat rozmieszczenia punktów pomiarowych na konstrukcji naczynia wydobywczego pokazano na rysunku 3. Czujniki pomiarowe o numerach 1,2,3,4 zostały naklejone na cięgna u nasady głowicy, pozostałe czujniki naklejono poniżej pierwszej ramy kosza - rysunek 3 . Przykładowo na rysunku nr 4 pokazano rozmieszczenie czujników 5,5' i 6,6 naklejonych poniżej pierwszej ramy kosza skipu [1]. Czujniki 5 i 5' oraz 6 i 6' 7 i 7'; 8 i 8' leżące odpowiednio naprzeciw ległych powierzchniach cięgna połączono w układzie półmostka do odpowiednich kanałów pomiarowych. Pozwoliło to na pomiar tylko tej części naprężenia która jest wywołana momentem zginającym w płaszczyźnie prostopadłej do płaszczyzny naklejenia czujników. 


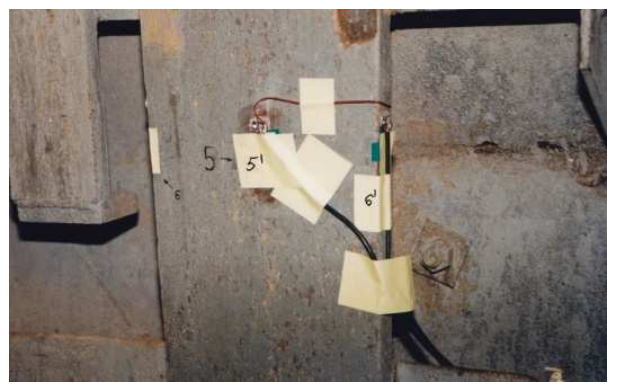

Rys. 4. Czujniki 5,5' i 6,6' naklejone powyżej pierwszej ramy kosza skipu po stronie lewej

Fig. 4. The sensors 5,5 'and 6,6' glued above the first frame on the left side of conveyances

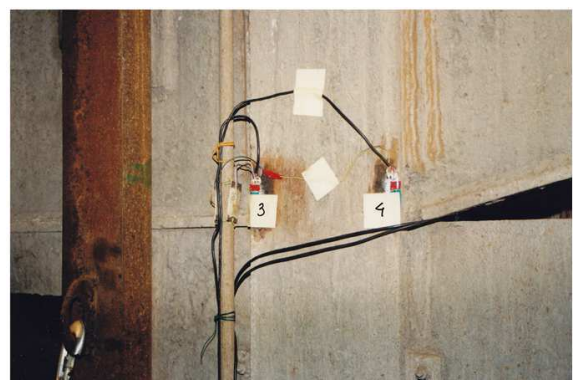

Rys. 5. Rozmieszczenie czujników na 3 i 4 u nasady głowicy na cięgnie

Fig. 5. Rlacement of sensors 3 and 4 at the base of the head in the conveyances on rods bearing elements

Natomiast na rysunku nr 5 pokazano rozmieszczenie czujników na 3 i 4 u nasady głowicy na cięgnie.

Po wyzerowaniu aparatury pomiarowej, uruchomiono maszynę wyciągową i rozpoczęto pomiar (przejazd), który obejmował pełny cykl pracy maszyny wyciągowej. W czasie pomiarów, jazda skipów odbywała się $\mathrm{z}$ prędkością $\mathrm{V}_{0}=20$ $\mathrm{m} / \mathrm{s}$, a wszystkie manewry odbywały się w taki sposób , jak w czasie normalnej pracy urządzenia wyciągowego. $\mathrm{W}$ trakcie przejazdów włączono dodatkowo znajdującą się na standardowym wyposażeniu wyciągu - aparaturę do pomiaru sił w linach.

Wyniki pomiarów, po ich odpowiednim opracowaniu przedstawiono w formie przebiegów zmian wartości naprężeń rejestrowanych w czasie, zamieszczono w monografii [1]. W referacie ograniczono się do zacytowania wyników pomiarów, dotyczących stanu naprężenia w przekroju poprzeczny cięgien, łączących głowicę z koszem skipu.

\section{Omówienie wyników pomiarów}

W celu lepszego zobrazowania wyników pomiarów - szczególnie w odniesieniu do naprężeń w cięgnach - wybrano odpowiednie fragmenty przebiegów naprężeń [1], i przedstawiono je w rozszerzonej skali czasowej. Rejestracja wyników w formie komputerowych zbiorów cyfrowych umożliwiła ich analizę. Taką analizę przeprowadzono posługując się programem MATLAB, a wyniki jej w formie graficznej przedstawiono na rysunkach $6 \div 9$.

$\mathrm{Z}$ porównania przebiegów zmiany wartości sił w linach nośnych (rysunek 6) z przebiegiem zmiany wartości naprężenia w niektórych punktach pomiarowych (np. w punkcie 3 - rys. 7.) widać podobieństwo tych przebiegów. Wykresy naprężeń wyglądają tak, jakby na wykres obrazujący przebieg zmiany sił w linach nośnych, nałożono zakłócenia. Zakłócenia te, wywołane są między innymi, siłami wzajemnego oddziaływania naczynia i zbrojenia, które są związane 
z efektami prowadzenia oraz z załadunkiem lub rozładunkiem skipu. Punkt zerowy naprężeń na tych wykresach, odpowiada w rzeczywistości wartościom naprężeń w punktach pomiarowych, wywołanych odpowiednio ciężarem konstrukcji oraz ciężarem urobku. Jak już wspomniano odpowiednie podłączenie czujników pomiarowych 6,7, i $8 \mathrm{w}$ układ półmostka, eliminuje w torze pomiarowym naprężenia wywołane rozciąganiem cięgna. Oznacza to, że w tych punktach pomiarowych rejestrowana jest tylko ta część naprężenia którą wywołuje moment gnący. Chodziło w tym przypadku o oszacowanie wartości naprężeń pochodzących od momentu gnącego - wywołanego siłami wzajemnego oddziaływania naczynia i zbrojenia i odniesienie ich, do wartości naprężeń wywołanych osiowym rozciąganiem cięgien.

W opracowaniu [7] przedstawiono zamiany wartości naprężeń w punkcie 1.

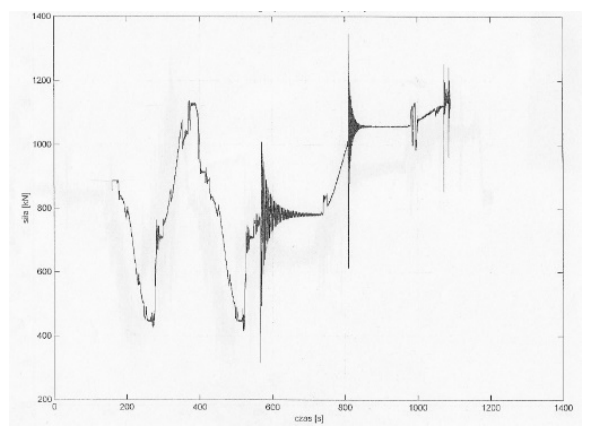

Rys. 6. Przebiegi sił w zawieszeniu - cały przejazd [1]

Fig. 6. Diagram of forces in the mine conveyance attachments - the entire journey [1]

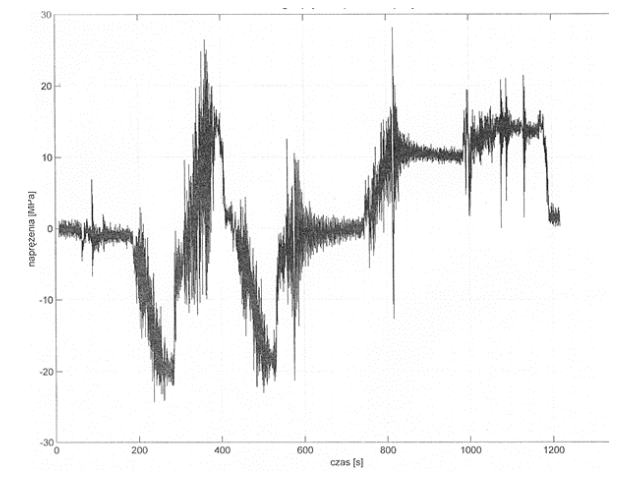

Rys. 7. Przebieg naprężeń w p.3

Fig. 7. Diagram of stress in point 3

Na rysunku 8 przedstawiono przebieg zmiany tych naprężeń w cięgnie, zarejestrowany przez czujnik 7 podczas zjazdu pustego naczynia do podszybia natomiast na rysunku 9 przebieg zmiany naprężenia, zarejestrowany przez ten sam czujnik, podczas wyjazdu pełnego naczynia, odpowiednio zwiększając , dla lepszej czytelności, skalę czasową (porównaj z rysunkiem nr 6). W opracowaniu [5] przedstawiono przebieg zmiany wartości naprężeń w cięgnie zarejestrowany przez czujnik 8.

W oparciu o wykonane pomiary [1] w tablicy 1 zebrano i przedstawiono wartości ekstremalnych przedziałów zmienności naprężeń wywołanych chwilowymi zmianami wartości obciążenia cięgna - siłami wzajemnego oddziaływania naczynia i zbrojenia szybu - oraz wartości ekstremalnych przedziałów zmienności naprężeń z uwzględnieniem współczynnika niejednorodności widma naprężeń. 


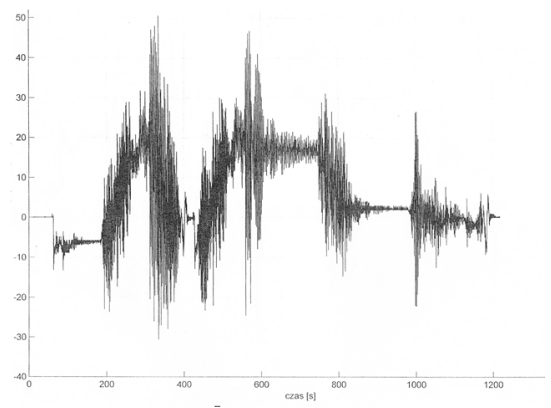

Rys. 8. Przebieg naprężeń w cięgnie w punkcie 7

Fig. 8. Diagram of stress in point 7 in rod

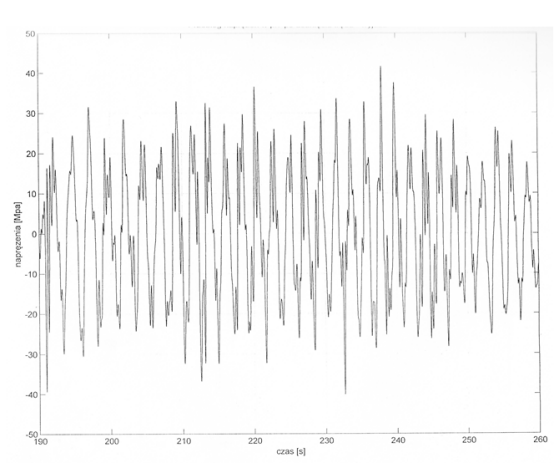

Rys. 9. Przebieg naprężeń w cięgnie w punkcie 7 po usunięciu trendu

Fig. 9. Diagram of stress in point 7 in rod. after removing the trend

Tablica 1. Przebieg zmienności naprężeń w pełnym cyklu pracy urządzenia wyciągowego (źródło: opracowanie własne na podstawie [1])

Table 1. The variation of stress in the full cycle hoist. (Source: own study based on [1])

\begin{tabular}{|c|c|c|}
\hline \multirow{2}{*}{ Punkt pomiarowy, Nr } & \multicolumn{2}{|c|}{ Max przedział zmienności naprężeń } \\
\cline { 2 - 3 } & $\Delta \sigma$ & $\alpha_{\mathrm{K}} \Delta \sigma$ \\
\hline 1 & 75 & 70 \\
\hline 2 & 50 & 47 \\
\hline 3 & 35 & 32,5 \\
\hline 4 & 25 & 24 \\
\hline 6 & 40 & 35 \\
\hline 7 & 75 & 71 \\
\hline 8 & 45 & 40 \\
\hline
\end{tabular}

Porównując przebieg zmiany siły w linach nośnych (rys. 6) z przebiegami jednocześnie mierzonych wartości naprężeń ([1], przykładowo rys. 7,8) wyliczono wartości współczynników korelacji. Wyliczone wartości współczynników korelacji zestawiono $w$ tablicy 2 . Szczególnie wysoka jest korelacja między siłą w linach a naprężeniami w punktach $1,2,3,4$. W punktach leżących w pobliżu spoin łączących cięgno z głowicą korelacja ta jest bardzo duża i jej współczynnik zawiera się $w$ granicach $0,89 \div 0.95$. Znacznie mniejsza jest korelacja pomiędzy siłą w linach i naprężeniami w punktach pomiarowych 6,7,8. Na przykład dla punktu pomiarowego 7 współczynnik korelacji wynosi 0.58 . Można szacować, że około $60 \%$ wartości naprężeń w tym punkcie ma związek z wartością siły w linach, pozostałe $40 \%$ jest powiązana $z$ siłami prowadzenia naczynia. Natomiast w odniesieniu do naprężeń w punkcie pomiarowym 6, wartość współczynnika korelacji wynosi 0.32 . Świadczy to o tym, że o wartości tego naprężenia w prawie $70 \%$ decyduje oddziaływanie sił prowadzenia naczynia. 
Tablica 2. Wartości współczynników korelacji pomiędzy wartością siły w linie nośnej a wartością naprężeń w punktach pomiarowych (źródło: opracowanie własne na podstawie [1])

Table 2. The values of correlation coefficients between the force in ropes and the value of stress at the measuring points (Source: own study based on [1])

\begin{tabular}{|l|c|c|c|c|c|c|c|c|}
\cline { 2 - 9 } \multicolumn{1}{c|}{} & Fzaw. & P1 & P2 & P3 & P4 & P6 & P7 & P8 \\
\hline Fzaw. & 1,0000 & 0,9458 & 0,9339 & 0,9400 & 0,8921 & 0,3221 & 0,5779 & 0,2376 \\
\hline P1 & 0,9458 & 1,0000 & 0,9541 & 0,9517 & 0,9256 & 0,3463 & 0,6329 & 0,3216 \\
\hline P2 & 0,9339 & 0,9541 & 1,0000 & 0,9743 & 0,9065 & 0,3451 & 0,5333 & 0,2199 \\
\hline P3 & 0,9400 & 0,9517 & 0,9743 & 1,0000 & 0,9071 & 0,3833 & 0,4871 & 0,1967 \\
\hline P4 & 0,8928 & 0,9256 & 0,9065 & 0,9071 & 1,0000 & 0,3387 & 0,5512 & 0,2542 \\
\hline P6 & 0,3221 & 0,3463 & 0,3451 & 0,3833 & 0,3387 & 1,0000 & 0,0319 & 0,7224 \\
\hline P7 & 0,5779 & 0,6329 & 0,5333 & 0,4871 & 0,5512 & 0,0319 & 1,0000 & 0,3785 \\
\hline P8 & 0,2376 & 0,3216 & 0,2199 & 0,1967 & 0,2542 & 0,7224 & 0,3785 & 1,0000 \\
\hline
\end{tabular}

Ponieważ obserwowane uszkodzenia cięgien wykazują charakter zmęczeniowy [1], opracowano wyniki pomiarów w taki sposób, aby możliwe stało się ich wykorzystanie do oceny trwałości zmęczeniowej konstrukcji naczynia wydobywczego [1].

Między innymi w tablicy 3 zestawiono wartości współczynników wypełnienia widma $\alpha_{\mathrm{k}}$ przebiegów naprężeń $\mathrm{w}$ punktach pomiarowych dla pełnego cyklu pracy wyciągu.

Tablica 3. Wartości współczynników wypełnienia widma $\alpha_{k}$ przebiegów naprężeń w punktach pomiarowych dla pełnego cyklu pracy wyciągu (źródło: opracowanie własne na podstawie [1])

Table 3. The values of coefficients fill spectral waveforms stress at the measuring points for the full cycle. (Source: own study based on [1])

\begin{tabular}{|l|c|c|c|c|c|c|c|c|}
\cline { 2 - 9 } \multicolumn{1}{c|}{} & P1 & P2 & P3 & P4 & P6 & P7 & P8 & $\begin{array}{l}\text { Wartość } \\
\text { średnia }\end{array}$ \\
\hline$\alpha_{k}$ dla m. $=3$ & 0,7489 & 0,7606 & 0,7459 & 0,8008 & 0,6857 & 0,7737 & 0,7184 & 0,7477 \\
\hline$\alpha_{k}$ dla m. =5 & 0,9312 & 0,9398 & 0,9289 & 0,9694 & 0,8832 & 0,9496 & 0,9082 & 0,93 \\
\hline $\begin{array}{l}\text { liczba cykli } \\
\text { naprężeń na } \\
\text { jeden przejazd }\end{array}$ & 636 & 637 & 626 & 608 & 596 & 467 & 564 & 591 \\
\hline
\end{tabular}

\section{Ocena trwałości zmęczeniowej cięgien konstrukcji skipu dla normalnych warunków eksploatacyjnych}

Na podstawie analizy liczby wyładunków naczyń wyciągowych w wybranych szybach [1][6], określono przeciętne liczby cykli obciążeń konstrukcji naczynia wydobywczego z czterech szybów z jednej z polskich kopalń, zakładając $50 \%$ cykli roboczych w sobotę oraz zero cykli w niedzielę i święta. Obliczone liczby cykli roboczych dla 10 i 15 lat pracy urządzenia wydobywczego zestawiono w tablicy 4 . W obliczeniach nie uwzględniono okresowych prac remontowych, zatem rzeczywiste liczby cykli obciążeń mogą być nieco mniejsze. 
Tablica 4. Liczba cykli roboczych oszacowane dla wybranych szybów (źródło: opracowanie własne na podstawie [4])

Table 4. The number of cycles estimated for the selected shafts (Source: own study based on [4])

\begin{tabular}{|c|c|c|}
\hline \multirow{2}{*}{ Oznaczenie szybów } & \multicolumn{2}{|c|}{ Liczby cyklów roboczych } \\
\cline { 2 - 3 } & 10 lat & 15 lat \\
\hline I & $0,58 \cdot 10^{6}$ & $0,87 \cdot 10^{6}$ \\
\hline II & $0,66 \cdot 10^{6}$ & $0,99 \cdot 10^{6}$ \\
\hline III & $0.68 \cdot 10^{6}$ & $1,02 \cdot 10^{6}$ \\
\hline IV & $0,58 \cdot 10^{6}$ & $0,86 \cdot 10^{6}$ \\
\hline
\end{tabular}

Na podstawie wyników zestawionych w tablicy 4 do dalszych obliczeń, jako liczbę cykli rocznych dla 15 lat pracy konstrukcji naczynia wydobywczego przyjęto $N=1 \cdot 10^{6}$.

Eurokod 3 standard [5] zaleca wytrzymałość zmęczeniową $\Delta \sigma_{R}$ i $\Delta \tau_{R}$ ustalić w zależności od przewidywanej liczby cykli naprężeń $N$ i kategorii zmęczeniowej elementu konstrukcji lub połączenia $\left(\Delta \sigma_{c}, \Delta \tau_{c}\right)$ według wzoru:

$$
\Delta \sigma_{R}=0,735 \Delta \sigma_{c}\left(\frac{5 \cdot 10^{6}}{N}\right)^{\frac{1}{m}} \geq \Delta \sigma_{L}
$$

gdzie: $m=3$ dla $N \leq 5 \cdot 10^{6} ; m=5$ dla $N>5 \cdot 10^{6}$

$\Delta \sigma_{c}$ - kategoria zmęczeniowa (wytrzymałość zmęczeniowa normatywna),

$\Delta \sigma_{L}$ - wytrzymałość zmęczeniowa trwała

Nośność konstrukcji wg [5] ze względu na zmęczenie należy sprawdzić wg wzoru

$$
\Delta \sigma_{C} \leq \frac{\Delta \sigma_{R}}{\gamma_{f a t}}
$$

gdzie: $\gamma_{\text {fat }}$ - częściowy współczynnik bezpieczeństwa przy zmęczeniu materiału, przyjmowany jako $\gamma_{\text {fat }}=1 \div 1,2$. Wartość współczynnika zależy od warunków eksploatacji, kontroli i konserwacji. Dla przeciętnych warunków norma [5] zaleca przyjmować $\gamma_{\text {fat }}=1$, a dla skrajnych $\gamma_{\text {fat }}=1,2$. Cięgna konstrukcji naczynia połączone są z głowicą, koszem skipu oraz ramą dolną spoinami pachwinowymi (ścinanie) $\mathrm{w}$ kierunku długości spoin, zatem wg [5] $\Delta \sigma_{c}=80 \mathrm{MPa}$ Stąd wytrzymałość zmęczeniowa cięgna naczynia wydobywczego wg zależności (1) wynosi:

$$
\Delta \sigma_{R}=0,735 \cdot 80 \cdot\left(\frac{5 \cdot 10^{6}}{1 \cdot 10^{6}}\right)^{\frac{1}{3}}=100[\mathrm{MPa}]
$$


Nośność konstrukcji wg [5] ze względu na zmęczenie należy sprawdzić wg wzoru (2). Dla przeciętnych warunków kontroli i konserwacji można przyjąć $\gamma_{\text {fat }}=1$,

Stąd $\Delta \sigma_{e} \leq \frac{\Delta \sigma_{c}}{\gamma_{f a t}}=\frac{100}{1} \cong 100 \mathrm{MPa}$

Konfrontując uzyskaną wartość $\Delta \sigma_{e} \mathrm{z}$ maksymalnymi zmiennościami naprężeń wyznaczonymi dla analizowanych punktów pomiarowych $\Delta \sigma$ (tablica 1) stwierdzono że naczynie wydobywcze można bezpiecznie eksploatować przez, 15 lat, ponieważ $\Delta \sigma<\Delta \sigma_{e}$.

Powyższe obliczenia wykonano, definiując cykl jako zmianę obciążenia związaną z załadunkiem i wyładunkiem naczynia. W rzeczywistości między załadunkiem a wyładunkiem naczynia, występuje cały blok zmiany naprężenia (porównaj rys. $6,7,8$ ). Numeryczna analiza wykazała, że pomiędzy w/w punktami naprężenia zmieniały się około $6 \cdot 10^{2}$ cykli (tablica 3 ).

W takim przypadku, jako liczbę cykli dla 15 lat pracy konstrukcji naczynia, należy przyjąć

$N \cong 6 \cdot 10^{2} \cdot 10^{6}=6 \cdot 10^{8}$.

Natomiast w przypadku niejednorodnego widma naprężeń, można przyjmować równoważny zakres zmienności naprężeń, określony wzorem [5]:

$\Delta \sigma_{e}=\alpha_{k} \cdot \max \Delta \sigma$

gdzie:

$\alpha_{k}-$ współczynnik niejednorodności (wypełnienia) widma (tab. 3).

Teraz $\Delta \sigma_{R}=0,735 \cdot \Delta \sigma_{c} \cdot\left(\frac{5 \cdot 10^{6}}{6 \cdot 10^{8}}\right)^{\frac{1}{5}} \cong 0,735 \cdot 80 \cdot \frac{1}{\sqrt[5]{120}}=23,5[\mathrm{MPa}]$.

Porównując uzyskaną wartość $\Delta \sigma_{R} \mathrm{z}$ wartością $\alpha_{k} \cdot \max \Delta \sigma$ (tablica 1) zauważamy że, bezpieczna eksploatacja przez okres 15 lat naczynia wydobywczego (na którym przeprowadzono eksperyment) jest bardzo wątpliwa. Tak wykonana analiza potwierdza fakt, pojawienia się pęknięć zmęczeniowych nawet po kilku latach eksploatacji skipu [1].

\section{Podsumowanie}

Analiza wyników pomiarów tensometrycznych wskazuje, że liczba rzeczywistych cykli obciążeń jest wielokrotnie większa niż cykli liczonych od załadunku do rozładunku [4]. Jeden cykl zmiany obciążenia związany z załadunkiem i wyładunkiem poprawniej będzie nazwać blokiem obciążenia.

Wykonana analiza trwałości zmęczeniowej cięgna naczynia wydobywczego, wskazuje na możliwość rozwoju pęknięć zmęczeniowych w najbardziej wytężonych obszarach konstrukcji, w krótkiej perspektywie czasowej. Tezę tę potwierdzają obserwacje naczyń wyciągowych eksploatowanych zarówno w górnictwie miedziowym i węglowym [1]. 
W świetle powyższego konieczne wydaje się wykonanie obszerniejszej analizy wytrzymałościowo-zmęczeniowej $\mathrm{w}$ aspekcie modernizacji naczynia wyciągowego, której celem byłoby podwyższenie jego trwałości zmęczeniowej. Przeprowadzenie takiej analizy stanowić może podstawę do opracowania kryterium oceny bezpiecznego okresu eksploatacji rozważanych urządzeń.

\section{Literatura}

[1] Wolny S., Wybrane problemy wytrzymałościowe w eksploatacji górniczych urządzeń wyciągowych. Monografia. Problemy Inżynierii Mechanicznej i Robotyki. AGH. Kraków, 2003 r.

[2] Kay K., 2010 Brake Control Strategy After-Stop Conveyance Oscillation and Haul. International Conference on Hoisting nad Haulage. Las Vegas, Nevada, United States.

[3] Thomas G.R. M.E. Greenway Shaft Stheel and Conveyance Dynamics. Conferens of Hoisting of Men, Materials and Minerals. Toronto 1988.

[4] Dziennik ustaw nr 99. Poz. 1003. Rozporządzenie Rady Ministrów z dnia 30 kwietnia 2004r., „, s sprawie dopuszczenia wyrobów do stosowania w zakładach górniczych”.

[5] Eurokod 3.

[6] Badura S., „Description of criterion of design of koepe pulleys of winding gears”. AGH Kraków 2008.

[7] Wytrzymałości cięgien nośnych górniczego naczynia wyciągowego w świetle obliczeń zmęczeniowych - Problem of strength of in hoisting strings of skip conveyances in the light of fatigue calculations / Stanisław WOLNY, Sławomir BADURA // W: Transport szybowy: monografia : praca zbiorowa / Instytut Techniki Górniczej KOMAG Gliwice : Instytut Techniki Górniczej KOMAG, 2015. - 1 dysk optyczny. - e-ISBN10: 978-8360708-89-7.

\section{THE STRENGTH OF RODS BEARING ELEMENTS IN CONVEYANCES}

\section{S u m m a r y}

Analysis of periodic tests conveyances and cage operated shafts in one of the mines revealed that most of the failures recorded in load-bearing elements in conveyances, is fatigue cracks. In order to eliminate the causes formation of damage and increased durability in conveyances, necessary will probably perform the reconstruction of the fragments conveyances in which the damage they are. To reconstruction brought the expected results, it is necessary to know the reasons being the source of emerging cracks. Therefore it was decided to carry out measurements the results of which allow you to determine the values of loads and a further assessment of their strength and durability.

The analysis of fatigue life rods-bearing elements in conveyances it indicates the possibility of the development of fatigue cracks in the most intensive areas of the construction, in the short term.

Keywords: conveyances, tension rods, strain gauge, fatigue life

Przestano do redakcji: $15.02 .2017 \mathrm{r}$.

Przyjęto do druku: 28.04.2017 r. 